Research Journal of Pharmacology and Pharmacy
(ISSN:2572-8377)

\title{
Antiparasitary Activity Of The Juglone Compound: A Narrative
} Review

\section{Paulo Henrique Valença Nunes ${ }^{1,2^{\star}}$, José Rafael da Silva Araújo ${ }^{2}$, Victor Hugo Barbosa dos Santos $^{1,2}$, Renan Andrade Fernandes de Souza ${ }^{1,2}$, André de Lima Aires ${ }^{1,2}$, Mônica Camelo Pessoa de Azevedo Albuquerque ${ }^{1,2}$}

${ }^{1}$ Laboratorio de Imunopatologia Keizo Asami; ${ }^{2}$ Universidade Federal de Pernambuco;

\begin{abstract}
Objective: To report, based on the literature, the action of the compound 5-hydroxy-1,4-naphthoquinone against parasites (protozoa and helminths) that affect humans. Methods: This is a narrative review that used Pubmed and Google Scholar as a data tool. This work included articles published until September 2020 that were directly related to the use of the compound juglone in antiparasitic trials. Results: The compound juglone demonstrated promising effects as a human and animal antiparasitic substance. In protozoa, the Apicomplexo Toxoplasma gondii parasite showed a high mortality rate in concentrations of juglone in the nanomolar range. The juglone showed an average inhibitory concentration (IC50) of $1.62 \mu \mathrm{M},>100 \mu \mathrm{M}$, and $2.02 \mu \mathrm{M} \mu \mathrm{M}$ for Trypanosoma cruzi, T. brucei rhodesiense, and Leishmania donovani, respectively. Also, the juglone showed antihelmintic activity on Hymenolepis nana in mice, and on adult worms of Schistosoma mansoni (LE strain) with IC50 $34.16 \mu \mathrm{M}, 32.14 \mu \mathrm{M}$, and $25 \mu \mathrm{M}$ in the $24 \mathrm{~h}, 48 \mathrm{~h}$, and $72 \mathrm{~h}$, respectively. Conclusion: The results published so far show the in vitro antiparasitic potential of juglone, and the need for further studies on the specific mode of action that interacts with parasites. Besides, the literature is still limited to studies that evaluate in vivo the compound juglone, re*Correspondence to Author: Paulo Henrique Valença Nunes Laboratorio de Imunopatologia Keizo Asami;

How to cite this article:

Paulo Henrique Valença Nunes, José Rafael da Silva Araújo, Victor Hugo Barbosa dos Santos, Renan Andrade Fernandes de Souza, André de Lima Aires, Mônica Camelo Pessoa de Azevedo Albuquerque. Antiparasitary Activity Of The Juglone Compound: A Narrative Review. Research Journal of Pharmacology and Pharmacy, 2021, 5:13.

quiring better information on its interaction with living organisms.

\section{eScî̀Pub}

eSciPub LLC, Houston, TX USA. Website: https://escipub.com/
\end{abstract}

Keywords: natural compounds, antirapasite, pharmacology activity 


\section{INTRODUCTION}

Currently, more than 3.5 million individuals worldwide are affected by one or more intestinal parasites (1). However, as they are considered endemic diseases only in poor regions and communities, little attention is paid to new forms of therapeutic practices (2). Despite this, there are growing efforts by researchers to address the neglect given to parasites that generate morbidity worldwide (3). Juglone is a naturally occurring naphthoquinone that has been widely studied due to its importance in biological and medicinal research (4). It is an amber-colored compound, solid, with low water solubility and good resistance to temperature variation. Its structure is described as 5-hydroxy-1,4naphthoquinone, abundantly extracted from stems, leaves, and seeds of different evolutionary stages of plants of the species Juglans nigra L., Juglans regia L., Juglans cinérea L., Juglans sieboldiana L., belonging to family Juglandaceae (4). Among these plant species, J. nigra is the most used in the extraction of juglone due to higher concentration of this compound in its anatomical parts (5). In traditional medicine, juglone plays a curative or palliative role in some diseases, as it has antibacterial (6), anti-inflammatory (7), antihypertensive (8), sedative (4) properties. Juglone has also been analyzed as a human and animal antiparasitic. In protozoa it obtained action under Toxoplasma gondii, Trypanosoma cruzi, T. brucei rhodesiense, and Leishmania donovani, while in helminths activity was observed on Hymenolepis nana, Meloidogyne spp. (9-11). Although the juglone has these biological aspects mentioned, its mechanism of action has not yet been fully elucidated.

\section{OBJECTIVE}

The report based on the literature about the action of the compound 5-hydroxy-1,4naphthoquinone against parasites (protozoa and helminths) that affect humans.

\section{METHODS}

This work is a narrative review that used the Pubmed and Google Scholar platforms as a data tool. This study included articles published until September 2020 that were directly related to the use of the compound juglone in antiparasitic tests. For that, the keywords "Juglona", "antiparasitic", "helminths", and "protozoa" in Portuguese and English were considered. Repetition of articles found in the data platforms and that was not associated with the antiparasitic activity of the juglone were excluded.

\section{RESULTS}

After carefully reading the articles provided by the platforms, five studies were selected. The compound juglone demonstrated promising effects as a human and animal anti-parasitic substance. In protozoa, the Apicomplexo Toxoplasma gondii parasite showed a high mortality rate in concentrations of juglone in the nanomolar range. The high specificity of juglone was observed in the intracellular parasite, with no effect on the host cell (12). Also, it was analyzed, through the technique of detection of endogenous oxidative stress, the direct action of juglone in the oxidative stress of $T$. gondii. For Trypanosoma cruzi, T. brucei rhodesiense, and Leishmania donovani, in vitro tests were carried out using different concentrations of aqueous extracts of Juglans spp., rich in juglone. Juglone showed an average inhibitory concentration $\left(\mathrm{IC}_{50}\right)$ of $1.62 \mu \mathrm{M},>100 \mu \mathrm{M}$, and $2.02 \mu \mathrm{M}$ for Trypanosoma cruzi, T. brucei rhodesiense, and Leishmania donovani (9). Juglone also showed antihelmintic activity on Hymenolepis nana in mice (10) and on adult Schistosoma mansoni worms (LE strain) (13). Magalhães demonstrated the anti-schistosomicidal capacity of juglone in adult worms, for 72 hours. In their analysis, the $\mathrm{IC}_{50}$ varied between $34.16 \mu \mathrm{M}$, $32.14 \mu \mathrm{M}$, and $25 \mu \mathrm{M}$ in the $24 \mathrm{~h}, 48 \mathrm{~h}$, and $72 \mathrm{~h}$ times, respectively. The extensive action of juglone was also evidenced in trials involving adult mollusks from Biomphalaria (Say, 1818), the intermediate host of $S$. mansoni in Brazil 
(14). The naphthoquinone compound can act on adult snails in low concentrations $\left(\mathrm{IC}_{50}=1.4\right.$ ppm).

\section{DISCUSSION}

Juglone is an antiparasitic present promising result, in vitro, as it is capable of acting directly against parasites, and indirectly, as an inflammatory, analgesic modulator and among others $(5,15)$. In traditional medicine, juglone plays a curative or palliative role in some diseases, as it has antibacterial (6), antiinflammatory (7), antihypertensive (5), and sedative (5) properties. Although the juglone has these biological aspects mentioned, its mechanism of action has not yet been elucidated. However, the antioxidant and oxidative capacity of naphthoquinone is known, making it a controversial molecule, capable of generating protection for the biological system and, at the same time, depending on the dose, causing injuries (16). Juglone and other naphthoquinones can modulate the redox cycle, a mechanism responsible for therapeutic actions in cancer and human infections (5). Through catalysis by the NADPH cytochrome P-450 reductase, NADPH cytochrome b5, or NADPH ubiquinone oxidoreductase enzymes, the juglone undergoes an electron reduction with subsequent formation of the semiquinone or hydroquinone radical (7). The reduced species, semiquinone, oxidizes by transferring an electron to an acceptor molecule, leading to the formation of bioactive species reactive to oxygen $\left(\mathrm{O}_{2^{-}} \bullet\right.$, HO- $\bullet, 1 \mathrm{O}_{2}$, and $\left.\mathrm{H}_{2} \mathrm{O}_{2}\right)$ (5). The superoxide anion can react with other cell structures, such as the $\mathrm{Fe}^{2+}$ transition metal, which by catalyzing or by reacting with hydrogen peroxide, generates hydroxyl radicals within the cell. Thus, the increased levels of the aforementioned radicals, inactivate enzymes, cause damage to the cell membrane, lipid peroxidation, protein denaturation, and DNA strand breaks, which can lead to cell death (1719). This is the main route of toxicity for juglone. However, studies also report the ability of juglone to deplete endogenous antioxidant agents, such as glutathione (GSH) (18). Through the GSH interaction with the juglone, there is an increase in cellular toxicity and a decrease in the amount of reduced glutathione, and thus there is an oxidative stress process (20). Such modulation in oxidative stress makes juglone a controversial molecule since these properties are capable of being effective against cancerous cell lines, such as human bladder carcinoma (TCC-SUB and RT-4), human leukemia cell line, including resistant to the drug doxorubicin, glioma (21), hepatoma (HepG2) (22); and cytotoxic, in a normal cell line, L929 fibroblasts from BALB mice and rat skeletal myoblasts $(9,23)$. Despite the observed data, in vivo studies aiming to evaluate the antiparasitic potential, using murine or human models, are not yet reported in the literature.

\section{CONCLUSIONS}

The results published so far show the in vitro antiparasitic potential of juglone, and the need for further studies on the specific mode of action that interacts with parasites. Also, the literature is still limited in vivo evaluations of the compound juglone, to test its application in living organisms.

\section{REFERENCES}

[1]. Meiga MZ, Souza JA de, Oliveira RN de, Rocha CS, Miné JC. Frequency of enteroparasites in individuals in the municipality of Ponta Grossa PR ( 2010-2016 ). O mundo da Saúde. 2018;42(3):744-61.

[2]. WHO WHO. What is schistosomiasis? [Internet]. 2017 [cited 2018 Feb 27]. Available from: http://www.who.int/schistosomiasis/en/

[3]. WHO WHO. Integrating neglected tropical diseases in global health and development: Fourth WHO report on neglected tropical disease. World Health Organization. Geneva: World Health Organization; 2017. 269 p.

[4]. Maryon P. Strugstad \& Saško Despotovski. and Potential Uses of Juglone: A Literature Review. J Ecosyst Manag. 2012;13(3):1-16.

[5]. Ahmad T, Suzuki YJ. Juglone in Oxidative Stress and Cell Signaling. antioxidants. 2019;8:91.

[6]. Kong Y, Xhang L, Yang Z, Han C, Hu L, Jiang 
Paulo Henrique Valença Nunes et al., RJPP, 2021; 5:13

$\mathrm{H}$, et al. Natural product juglone targets three key enzymes from Helicobacter pylori : inhibition assay with crystal structure characterization 1. Acta Pharmacol Sin. 2008;29(7):870-6.

[7]. Landa P, Kutil Z, Temml V, Vuorinen A, Malik J, Dvorakova $M$, et al. Redox and Non-Redox Mechanism of In Vitro Cyclooxygenase Inhibition by Natural Quinones. Planta Med. 2012;78:326-33.

[8]. Ahmad T, Khan T, Shah AJ. Juglone as antihypertensive agent acts through multiple vascular mechanisms. Clin Exp Hypertens [Internet]. 2019;00(00):1-10. Available from: https://doi.org/10.1080/10641963.2019.166567 4

[9]. Ellendorff T, Brun R, Kaiser M, Sendker J, Schmidt TJ. PLS-Prediction and Confirmation of Hydrojuglone Glucoside as the Antitrypanosomal Constituent of Juglans Spp. Molecules. 2015;10082-94.

[10]. Dama L.B. and Jadhav B.V. Anthelmintic effect of Juglone on mature and Immature Hymenolepis nana in mice. Riv di Parassitol. 1997;(2):301-2.

[11]. L.B. D, B.N. P, B.V J, MD H. "Effect of Herbal "Juglone" on Development of the plant parasitic nematode (Meloidogyne Spp.) on Arachis hypogaea. Ecotoxicol Environ Monit. 1999;(9):73-5.

[12]. Akerman SE, Mu S. Peroxiredoxin-linked Detoxification of Hydroperoxides in Toxoplasma gondii *. J Biol Chem. 2005;280(1):564-70.

[13]. Magalhães LG, Ra GS, Soares IAO, Badocco $F R$, Cunha WR, Rodrigues V. Journal of Tropical Diseases Chemoprevention of Schistosomiasis : In vitro Antiparasitic Activity of Nineteen Plant-derived and Synthetic Simple Naphthoquinones and Naphthols against Schistosoma Mansoni Adult Worms. J Trop Dis. 2014;2(4).

[14]. Ribeiro KAL, Monteiro C, Carvalho D, Teresa M, Pereira E, López-montero E, et al. Activities of naphthoquinones against Aedes aegypti ( Linnaeus, 1762 ) ( Diptera: Culicidae ), vector of dengue and Biomphalaria glabrata ( Say , 1818 ), intermediate host of Schistosoma mansoni. Acta Trop. 2009;111:44-50.

[15]. Catanzaro E, Greco G, Potenza L, Calcabrini C, Fimognari C. Natural Products to Fight Cancer: A Focus on Juglans regia. Toxins (Basel). 2018;10:469.

[16]. Eweas AF, Allam G. Molecular \& Biochemical Parasitology Targeting thioredoxin glutathione reductase as a potential antischistosomal drug target. Mol Biochem Parasitol [Internet].
2018;225(October):94-102. Available from: https://doi.org/10.1016/j.molbiopara.2018.09.00 4

[17]. Verma RP. Anti-Cancer Activities of 1 , 4Naphthoquinones: A QSAR Study. Anticancer Agents Med Chem. 2006;6:489-99.

[18]. Kiran Aithal B, Sunil Kumar MR, Nageshwar Rao B, Udupa N, Satish Rao BS. Juglone, a naphthoquinone from walnut, exerts cytotoxic and genotoxic effects against cultured melanoma tumor cells. Cell Biol Int [Internet]. 2009;33(10):1039-49. Available from: http://dx.doi.org/10.1016/j.cellbi.2009.06.018

[19]. Sajadimajd S, Yazdanparast R, Roshanzamir F. Augmentation of oxidative stress-induced apoptosis in MCF7 cells by ascorbate tamoxifen and / or ascorbate - juglone treatments. IThe Soc Vitr Biol. 2015;

[20]. Wang X, Thomas B, Sachdeva R, Arterburn L, Frye $L$, Hatcher $P G$, et al. Mechanism of arylating quinone toxicity involving Michael adduct formation and induction of endoplasmic reticulum stress. Proc Natl Acad Sci U S A. 2006;103(10):3604-9.

[21]. Wu J, Zhang H, Xu Y, Zhang J, Zhu W, Zhang $Y$, et al. Juglone induces apoptosis of tumor stem-like cells through ROS-p38 pathway in glioblastoma. BMC Neurol. 2017;1-7.

[22]. Wang $P$, Gao C, Wang W, Yao L, Zhang J, Zhang $S$, et al. Juglone induces apoptosis and autophagy via modulation of mitogen-activated protein kinase pathways in human hepatocellular carcinoma cells. Food Chem Toxicol. 2018;18(30206-0):S0278-6915.

[23]. Erisen S, Arasoğlu T, Mansuroglu B, Kocacaliskan I, Derman S. Cytotoxic and mutagenic potential of juglone : a comparison of free and nano-encapsulated form. Arh Hig Toksikol. 2020;71:69-77. 